\title{
SUPERAÇÃO DA DORMÊNCIA DE SEMENTES DE MUCUNA-PRETA PELA UTILIZAÇÃO DE "CALOR SECO"
}

\author{
E.B. WUTKE ${ }^{1}$; J.A. MAEDA ${ }^{2}$; R.M. PIO ${ }^{3}$ \\ ' Seção de Leguminosas/IAC - C.P.28, CEP:13.001-970- Campinas,SP \\ ${ }^{2}$ Seção de Sementes/IAC - C.P.28, CEP: 13.001-970 - Campinas, SP \\ ${ }^{3}$ Centro de Citricultura Sylvio Moreira - IAC - C.P.28, CEP: 13.001-970 - Campinas, SP
}

RESUMO: Avaliou-se a germinação de sementes recém-colhidas de mucuna preta (Mucuna aterrima) apos tratamento com "calor seco", em estufa elétrica com ventilação forçada, nas temperaturas de 35,45 e $55^{\circ} \mathrm{C}$, por períodos de exposição correspondentes a $0,2,4,6,8,16,24,48,72$ e 96 horas. A temperatura de $55^{\circ} \mathrm{C}$ foi adequada para a superação da impermeabilidade do tegumento da semente, sendo mais efetivos os perfodos de exposição entre 16 e 24 horas.

Descritores: Mucuna preta, Mucuna aterrima, dormência de sementes, calor seco, germinaçăo

\section{OVERCOMING VELVET BEAN SEED DORMANCY BY "DRY HEAT"}

ABSTRACT: The germination of freshly harvested velvet bean (Mucuna aterrima) seeds was evaluated after "dry heat" treatments under 35,45 and $55^{\circ} \mathrm{C}$, during periods of $0,2,4,6,8,16,24,48,72$ and 96 hours. The temperature of $55^{\circ} \mathrm{C}$ was satisfactory to overcome the impermeability of the seed coat, and the exposing periods between 16 and 24 hours were the most effective.

Key words: velvet bean, Mucuna aterrima, seed dormancy, dry heat, germination

\section{INTRODUÇÃO}

A mucuna-preta (Mucuna aterrima (Piper \& Tracy) Merr.), planta utilizada na adubação verde, é uma leguminosa que apresenta ocorrência de sementes duras. Conforme Cf́CERO (1986), a intensidade da dormência não é a mesma para todas as sementes do lote $\mathrm{e}$, essas germinam de maneira irregular ao longo do tempo. Segundo MAEDA \& LAGO (1986a), lotes de sementes dessa espécie podem apresentar 60 a $80 \%$ de sementes duras logo após a colheita, o que causa problemas no caso de necessidade de semeadura imediata, de comercialização ou, até mesmo, na determinação de viabilidade em laboratório. Além disso, a partir destas sementes podem ser estabelecidas, posteriormente, plantas indesejáveis nas culturas subsequëntes (TRAN \& CAVANAGH, 1984) o que explica, em parte, a relutância de inclusão dessa leguminosa em alguns sistemas de produção vigentes.

A expressiva longevidade das sementes de mucuna-preta pode ser atribuída à dureza de seu tegumento, que oferece proteção, principalmente contra danos mecânicos e invasão por microrganismos, dois importantes fatores do processo de deterioração de sementes (MAEDA \& LAGO, 1986b). Segundo MAEDA \& LAGO (1986b), a escarificação de sementes dessa espécie, para fins de semeadura, parece ser desnecessária, uma vez que o índice de sementes duras diminui sensivelmente nos primeiros meses, tornando-se irrelevante após seis meses de armazenamento.

A utilização de calor seco é um método empregado em laboratório, para a superação da impermeabilidade do tegumento, com consequiente germinação das sementes consideradas duras. Dentre os trabalhos que utilizaram essa técnica podem ser citados os de ROLSTON (1978), ALMEIDA et al. (1979) e FIGUEIREDO \& POPINIGIS (1979).

MAEDA \& LAGO (1986a) obtiveram, como métodos mais efetivos para superação da dureza do tegumento de sementes de mucuna-preta, os referentes à remoção de pequena porção do tegumento na região distal da semente (oposta ao 
eixo embrionário) e à imersão em ácido sulfúrico concentrado por $5,10,15$ e 20 minutos, que permitiram a obtenção de germinação das sementes superior a $88 \%$. Esses tratamentos esclarecem o motivo da dormência; porém, não fornecem condições de serem utilizados na prática porque a remoção de porção do tegumento, realizada em cada semente, é inviável para o agricultor que trabalha com grande quantidade de material e, a imersão em ácido sulfúrico apresenta o inconveniente do perigo da manipulação, desvantagens essas apontadas pelos próprios autores.

Como um método prático adotado pelo agricultor é a exposição dessas sementes recém-colhidas ao sol, o presente trabalho teve como objetivo estudar o efeito da utilização de calor seco sobre a germinação de sementes de mucuna-preta.

\section{MATERIAL E MÉTODOS}

O presente trabalho foi desenvolvido nos laboratórios das Seções de Leguminosas e de Sementes do Instituto Agronômico, em Campinas, SP.

Os materiais utilizados foram dois lotes de sementes de mucuna-preta produzidos em setembro de 1994, nas Estações Experimentais do Instituto Agronômico de Campinas localizadas em Adamantina (lote A) e Votuporanga (lote B). Dos lotes foram retiradas amostras de $10,0 \mathrm{~kg}$, que, beneficiadas, foram separadas em três categorias de tamanho - pequena, média e grande, correspondendo, respectivamente, às sementes retidas nas peneiras de crivos circulares $n^{\circ} 23,26$ e 29 (Tabela 1). Foram utilizadas, apenas, as de tamanho médio, que predominaram em ambos os lotes e que apresentaram a mesma frequûência de dureza entre as peneiras.

Para melhor caracterização dos lotes, determinou-se a massa de cem sementes (ainda na Tabela 1) e, atendendo às recomendações preconizadas nas Regras para Análise de Sementes, como tratamento especial para superar a dormência em sementes de Mucuna aterrima (BRASIL,1992), realizou-se, preliminarmente, um tratamento adicional (escarificação mecânica da semente), constando de corte de uma pequena porção da testa na extremidade dos cotilédones.

Como tratamento de calor seco, as sementes foram submetidas às temperaturas constantes de 35 , 45 e $55^{\circ} \mathrm{C}$, em estufas elétricas FANEM dotadas de ventilação forçada, por diferentes períodos de exposição $(0,2,4,6,8,16,24,48,72$ e 96 horas).

Após cada período de exposição ao calor nas diferentes temperaturas, foram retiradas amostras para a determinação do teor de água das sementes (método da estufa, $105^{\circ} \mathrm{C} \pm 3^{\circ} \mathrm{C}$, durante 24 horas, utilizando-se duas sub-amostras por repetição) e para a realização de teste de germinação em papel toalha, à temperatura constante de $30^{\circ} \mathrm{C}$, com contagens aos 3, 8 e 14 dias (BRASIL, 1992). Foram consideradas sementes duras, aquelas que permaneceram sem absorver água, apresentandose não intumescidas até o final do teste.

$O$ delineamento experimental utilizado foi inteiramente casualizado, em arranjos fatoriais $3 \mathrm{x}$ 10, para os tratamentos com calor em cada lote $e$ 2x 2 para os tratamentos sem e com corte para cada lote, com quatro repetições de 50 sementes

TABELA 1 - Freqüências de tamanhos e de dureza em sementes de mucuna-preta de Adamantina (lote A) e de Votuporanga (lote B).

\begin{tabular}{|c|c|c|c|c|}
\hline Lote & $\begin{array}{l}\text { tamanho da } \\
\text { semente }\end{array}$ & $\begin{array}{c}\text { frequência de } \\
\text { cada tamanho no } \\
\text { lote original }\end{array}$ & $\begin{array}{c}\begin{array}{c}\text { frequência } \\
\text { de sementes } \\
\text { duras }\end{array} \\
\end{array}$ & $\begin{array}{c}\text { massa } \\
\text { de } 100 \\
\text { sementes }\end{array}$ \\
\hline & & & & $\mathbf{g}$ \\
\hline & Pequena & 10,0 & 56,0 & 51,6 \\
\hline \multirow[t]{3}{*}{$\mathbf{A}$} & Média & 78,8 & 54,0 & 72,9 \\
\hline & Grande & 11,2 & 52,0 & 103,3 \\
\hline & Pequena & 9,6 & 71,0 & 54,0 \\
\hline \multirow[t]{2}{*}{ B } & Média & 76,7 & 70,0 & 77,8 \\
\hline & Grande & 13,7 & 74,0 & 109,2 \\
\hline
\end{tabular}


cada. Na análise estatística, os dados em percentagem foram transformados em arco seno $\sqrt{\% / 100}$, e a comparação de médias efetuada pelo teste de Tukey a 5\% (GOMES, 1984).

\section{RESULTADOS E DISCUSSÃO}

A classe predominante foi a de tamanho médio, para ambos os lotes. As percentagens de sementes duras, nos três tamanhos, não diferiram entre si, para um mesmo lote, contrariando NIMER et al.(1983) e BARBEDO et al.(1988), que observaram maior percentagem de dureza nas sementes menores dessa espécie.

Os valores obtidos nos testes de germinação das sementes "sem corte" e daquelas escarificadas fisicamente (tratamento adicional, com corte), em ambos os lotes, estão relacionados na Tabela 2.

Verifica-se que, em ambos os lotes, o tratamento "com corte" permitiu reduzir a zero a percentagem de sementes duras e elevar a percentagem de plântulas normais, o que confirma ser o tegumento uma barreira à germinação da semente. Esse resultado concorda com os obtidos por MAEDA \& LAGO (1986a). Conforme ÁQUILA \& FETT NETO (1988), a escarificação mecânica é efetiva na promoção da germinação; quando o tegumento é perfurado a entrada de água conduz à germinação.

Os dados germinação, de taxa de sementes duras e o teor de água das sementes não escarificadas, submetidas ao tratamento de calor seco estão relacionados nas Tabelas 3, 4 e 5 .
As análises de variância mostraram significância para efeito de temperaturas e para horas de exposição ao calor seco. $A$ interação entre os tratamentos foi significativa, conforme evidenciado nas tabelas apresentadas.

Verifica-se que a utilização da temperatura de $55^{\circ} \mathrm{C}$ por 16 e 24 horas foram os tratamentos mais efetivos para a superação da dormência das sementes de lotes com frequêencia inicial de dureza ao redor de 50 e $70 \%$, respectivamente. Os valores de germinação aumentaram de 34,2 para $55,5 \%$ no lote A e de 19,5 para $55,6 \%$ no lote $B$, sendo reduzidos em períodos de exposição superiores aos referidos acima (Tabela 3).

Quanto às sementes duras, os menores valores em relação às testemunhas foram obtidos na temperatura de $55^{\circ} \mathrm{C}$, nos tempos de exposição entre 2 a 8 horas para o lote A e entre 24 e 96 horas para o lote $B$ (Tabela 4). A redução percentual da dureza foi mais acentuada no lote $B$, particularmente a partir do período de exposição de 24 horas, evidenciando o efeito benéfico da exposição ao calor seco, sendo este maior quando se observa elevada ocorrência de sementes duras no lote.

Segundo ALMEIDA et al. (1979), o tratamento com calor seco, à temperatura constante de $65^{\circ} \mathrm{C}$ por 4 horas não permitiu obter resultados satisfatórios quanto à superação da dormência das sementes de soja-perene, centrosema, siratro e calopogônio, quando o tratamento foi efetuado imediatamente após a colheita ou, até mesmo, após um período de 36 meses de armazenamento. Por

TABELA 2 - Germinação de sementes de mucuna-preta procedentes de Adamantina (lote A) e de Votuporanga (lote B), submetidas ou não ao tratamento de escarificação mecânica.

\begin{tabular}{|c|c|c|c|c|c|c|}
\hline \multirow[t]{2}{*}{ Lote } & \multirow{2}{*}{$\begin{array}{l}\text { Condiçāo do } \\
\text { tegumento }\end{array}$} & \multicolumn{5}{|c|}{ teste de germinação } \\
\hline & & $\begin{array}{l}\text { plânt. } \\
\text { norm. }\end{array}$ & $\begin{array}{l}\text { plânt. } \\
\text { anorm. }\end{array}$ & $\begin{array}{l}\text { plânt. } \\
\text { infect. }\end{array}$ & $\begin{array}{l}\text { sem. } \\
\text { duras }\end{array}$ & $\begin{array}{l}\text { sem. } \\
\text { mortas }\end{array}$ \\
\hline \multirow{2}{*}{$\mathbf{A}$} & & $340 \mathrm{~h}$ & & $75 \mathrm{~h}$ & & $75 \mathrm{~h}$ \\
\hline & Com apara & $64,0 \mathrm{a}$ & $0,0 \mathrm{~b}$ & $31,00 \mathrm{a}$ & $0,0 \mathrm{~b}$ & $5,00 \mathrm{a}$ \\
\hline \multirow[t]{2}{*}{ B } & Sem apara & $19,5 \mathrm{~b}$ & $4,5 a$ & $2,00 \mathrm{~b}$ & $70,0 \mathrm{a}$ & $4,00 \mathrm{~b}$ \\
\hline & Com apara & 47,5 a & $0,0 \mathrm{~b}$ & $44,50 \mathrm{a}$ & $0,0 \mathrm{~b}$ & $8,00 \mathrm{a}$ \\
\hline CV \% & & 24,22 & 23,16 & 38,44 & 5,16 & 31,54 \\
\hline
\end{tabular}

Médias seguidas por mesmas letras na coluna não diferem significativamente entre si a $5 \%$. 
outro lado, obtiveram êxito do tratamento em sementes de kudzu-tropical. Os autores, entretanto, não avaliaram outras combinações de temperatura e de tempo de exposição ao calor seco.

FIGUEIREDO \& POPINIGIS (1979) obtiveram germinação de $68 \%$ para sementes de malva, submetidas a aquecimento de $90^{\circ} \mathrm{C}$ por 2 horas, enquanto a testemunha apresentou $23 \%$. Segundo os autores, o aquecimento a 40,50,60 e $70^{\circ} \mathrm{C}$, por tempos de exposição variáveis, não resultou em quebra satisfatória de dormência.

Diante disso, pode-se esperar comportamentos diferenciados, como resposta a tratamentos para superação desse tipo de dormência, segundo a espécie considerada. Para a mucuna-preta, à semelhança do observado em sementes de alfafa (ELLIS \& PALMER, 1973); amendoim (SHARIR, 1978); leguminosas forrageiras (ALMEIDA et al., 1979); Leucaena leucocephala (DUBOC et al., 1993); Trifolium resupinatum $\mathrm{L}$. e Adesmia muricata var. muricata (Jacq.) DC (MEDEIROS et al., 1993); Acacia longifolia Willd. (BRUM et al., 1995) e Brachiaria brizantha (LAGO \& MARTINS, 1995), o tratamento com calor seco, particularmente à temperatura de $55^{\circ} \mathrm{C}$, provoca efeito satisfatório para quebra de dormência.

Os valores obtidos (Tabela 3), contudo, foram mais satisfatórios do que aqueles observados por MAEDA \& LAGO (1986 a), que obtiveram ao redor de $30,0 \%$ de germinação em sementes de mucuna-preta recém-colhidas $(75 \%$ de sementes duras e $23,9 \%$ de germinação) e submetidas ao calor seco a $65^{\circ} \mathrm{C}$ por $4 \mathrm{e} 6$ horas. Entretanto, as diferenças de resposta podem ser devidas à utilização de materiais de procedências e históricos de produção distintos, conforme evidenciado em outras espécies (JESUS \& PIÑA-RODRIGUES, 1991; MALUF, 1992; EIRA et al., 1993).

Também, a temperatura mais elevada estudada por MAEDA \& LAGO (1986 a) pode ter sido prejudicial à germinação das sementes dessa leguminosa. Conforme observado no tratamento de calor seco a 100 e $125^{\circ} \mathrm{C}$ por 1 a 24 horas em sementes de ervilhaca (BRANT et al., 1971) e a $95^{\circ} \mathrm{C}$ por 12 horas em Stylosanthes guianensis (Aubl.) SW (ARAÚJO et al., 1995), o problema da impermeabilidade do tegumento foi superado; porém, verificaram-se acréscimos nas percentagens de plântulas anormais e ou de sementes mortas.

O teor de água das sementes, em ambos os lotes, foi reduzido nas três temperaturas com o aumento dos períodos de exposição (Tabela 5). Entretanto, essa redução foi significatica e particularmente acentuada à temperatura de $55^{\circ} \mathrm{C}$, nos períodos de exposição de 16 e 24 horas ao calor seco, respectivamente para os lotes A e B, quando também se observaram os maiores valores de percentagem de plântulas normais nesses lotes (Tabela 3).

Inicialmente, a redução no teor de água das sementes foi acompanhada de redução na percentagem de dureza até os períodos de exposição de 6 a 8 horas, à exceção do obtido para o lote $B$, na temperatura de $55^{\circ} \mathrm{C}$. A partir de então, verificou-se uma tendência para o aumento desse parâmetro, confirmando observações de HARRINGTON (1949) e de BEWLEY \& BLACK (1982). Segundo os últimos autores, o grau de umidade é um dos fatores determinantes desse tipo de dormência, uma vez que os tegumentos das sementes tornam-se progressivamente duros e impermeáveis à medida que o grau de umidade dimunui.

A utilização de calor seco na temperatura de $55^{\circ} \mathrm{C}$, por período entre 16 e 24 horas, portanto, pode ser considerado um método satisfatório, prático e não prejudicial para a superação da dormência em sementes recémcolhidas de mucuna-preta. Também, pode ser empregado em larga escala, devido à facilidade de sua aplicação e à obtenção de aumento na germinação das sementes, possibilitando sua semeadura ou utilização imediata. Além disso, os riscos e dificuldades desse método são muito reduzidos ou quase inexistentes, sobretudo em relação à imersão em ácido sulfúrico concentrado por 5 a 20 minutos e à escarificação mecânica (corte de pequena porção do tegumento), que são aqueles métodos comprovadamente mais efetivos, segundo MAEDA \& LAGO (1986 a). Isso enfatiza a importância prática dos resultados obtidos neste trabalho e a viabilidade de sua adoção pelos agricultores. 
TABELA 3 - Percentagem de germinação de sementes de mucuna-preta recém-colhidas, procedentes de Adamantina (lote A) e de Votuporanga (lote B), após perfodos de exposição ao calor seco, em diversas temperaturas.

\begin{tabular}{|c|c|c|c|c|}
\hline \multirow[t]{2}{*}{ LOTE/Tempos de exposição } & \multicolumn{3}{|c|}{ Temperatura } & \multirow[t]{2}{*}{ Média } \\
\hline & $35^{\circ} \mathrm{c}$ & $45^{\circ} \mathrm{C}$ & $55^{\circ} \mathrm{C}$ & \\
\hline & & - $\%$ & 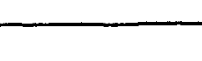 & 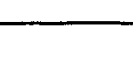 \\
\hline Lote $A / O$ hs & $34,2 \mathrm{aA}$ & $34,2 \mathrm{~b} \mathrm{~A}$ & $34,2 \mathrm{de} A$ & $34,2 b c$ \\
\hline$/ 2 \mathrm{hs}$ & $36,4 \mathrm{a} A \mathrm{AB}$ & $30,5 b \quad$ B & 42,4abcd A & $36,4 b c$ \\
\hline$/ 4 \mathrm{hs}$ & $26,2 \mathrm{a}$ B & $29,0 \mathrm{~B} \mathrm{~B}$ & $48,5 \mathrm{abc} \mathrm{A}$ & $34,5 \mathrm{bc}$ \\
\hline $16 \mathrm{hs}$ & $33,0 \mathrm{a} \mathrm{A}$ & $36,4 \mathrm{ab} \mathrm{A}$ & 37,5 bcde A & $35,6 \mathrm{bc}$ \\
\hline $18 \mathrm{hs}$ & $34,0 \mathrm{a} \mathrm{A}$ & $40,5 \mathrm{ab} \mathrm{A}$ & 44,5abcd A & $39,6 \mathrm{ab}$ \\
\hline$/ 16$ hs & $36,8 \mathrm{a} \mathrm{B}$ & $41,5 \mathrm{ab} \mathrm{B}$ & $55,5 \mathrm{a} \quad \mathrm{A}$ & $44,6 a$ \\
\hline$/ 24 \mathrm{hs}$ & $37,5 a \mathrm{~B}$ & $47,5 \mathrm{a} A B$ & $50,0 \mathrm{ab} \quad \mathrm{A}$ & $45,0 a$ \\
\hline /48 hs & $33,2 \mathrm{aA}$ & $38,9 \mathrm{ab} \mathrm{A}$ & 36,5cde A & $36,2 \mathrm{bc}$ \\
\hline$/ 72$ hs & $26,9 \mathrm{a}$ B & $34,3 \mathrm{ab} \mathrm{AB}$ & $42,0 \mathrm{bcd} A$ & $34,4 b c$ \\
\hline $196 \mathrm{hs}$ & $26,7 \mathrm{a} \mathrm{B}$ & 38,5ab A & $28,4 \mathrm{e} \quad \mathrm{AB}$ & $31,2 \mathrm{c}$ \\
\hline Média & $32,4 \mathrm{C}$ & 37,0 B & $41,8 \quad A$ & \\
\hline Lote B/ O hs & $19,5 \mathrm{aA}$ & $19,5 \mathrm{c} \mathrm{A}$ & $19,5 \mathrm{e} \quad \mathrm{A}$ & $19,5 d$ \\
\hline$/ 2 \mathrm{hs}$ & $22,5 \mathrm{aA}$ & $21,4 b c A$ & 23,4 de A & $22,4 \mathrm{~cd}$ \\
\hline$/ 4 \mathrm{hs}$ & $24,0 \mathrm{aA}$ & $24,5 \mathrm{abcA}$ & $35,4 b c d A$ & $27,9 \mathrm{bc}$ \\
\hline $16 \mathrm{hs}$ & $29,5 \mathrm{a} \mathrm{A}$ & $24,2 \mathrm{abcA}$ & 27,9 de $A$ & $27,2 b c$ \\
\hline $18 \mathrm{hs}$ & $28,9 \mathrm{a} A$ & $34,3 \mathrm{a} \quad \mathrm{A}$ & $30,9 \mathrm{cde} A$ & $31,3 \mathrm{ab}$ \\
\hline$/ 16 \mathrm{hs}$ & $24,5 \mathrm{a} \mathrm{B}$ & $30,9 \mathrm{abcB}$ & $45,5 \mathrm{ab} \quad A$ & $33,6 a b$ \\
\hline$/ 24 \mathrm{hs}$ & $28,3 a \mathrm{~B}$ & $31,9 \mathrm{ab} \mathrm{B}$ & $55,6 a \quad A$ & $38,6 a$ \\
\hline /48 hs & $25,4 a$ B & $24,5 \mathrm{abcB}$ & $43,4 \mathrm{abc} A$ & $31,1 \mathrm{ab}$ \\
\hline$/ 72$ hs & $27,8 \mathrm{a}$ B & $24,4 \mathrm{abcB}$ & 44,5abc A & $32,2 \mathrm{ab}$ \\
\hline $196 \mathrm{hs}$ & $18,3 \mathrm{a} \mathrm{B}$ & $27,8 \mathrm{abcB}$ & $41,4 \mathrm{bc} \quad \mathrm{A}$ & $29,2 \mathrm{bc}$ \\
\hline Média & $24,8 \mathrm{~B}$ & $26,2 \mathrm{~B}$ & $36,4 \quad A$ & \\
\hline
\end{tabular}

Médias seguidas pela mesma letra minúscula na coluna e maiúscula na linha, para cada lote, não diferem significativamente entre si a $5 \%$. 
TABELA 4 - Percentagem de dureza em sementes de mucuna-preta recém-colhidas, procedentes de Adamantina (lote A) e de Votuporanga (lote B), após diferentes períodos de exposição ao calor seco, a diversas temperaturas.

\begin{tabular}{|c|c|c|c|c|}
\hline \multirow[t]{2}{*}{ LOTE/Tempos de exposição } & \multicolumn{3}{|c|}{ TEMPERATURAS } & \multirow[t]{2}{*}{ MÉdIA } \\
\hline & $35^{\circ} \mathrm{C}$ & $45^{\circ} \mathrm{C}$ & $55^{\circ} \mathrm{C}$ & \\
\hline Lote A/ 0 hs & $54,0 \mathrm{ab} \mathrm{A}$ & $54,0 \mathrm{ab} A$ & $54,0 \mathrm{a} \quad \mathrm{A}$ & $54,0 \mathrm{ab}$ \\
\hline$/ 2 \mathrm{hs}$ & $49,5 \mathrm{~b}$ A & $45,9 \mathrm{abc} A B$ & $37,4 b \quad$ B & $44,2 \mathrm{c}$ \\
\hline$/ 4 \mathrm{hs}$ & $53,0 \mathrm{ab} \mathrm{A}$ & $51,5 \mathrm{ab} A$ & $36,4 b \quad B$ & $46,9 \mathrm{bc}$ \\
\hline $16 \mathrm{hs}$ & $47,5 \mathrm{~b} \quad \mathrm{~A}$ & $37,5 \mathrm{c} \quad \mathrm{AB}$ & $38,5 \mathrm{~b} \quad \mathrm{~B}$ & $41,1 \mathrm{c}$ \\
\hline$/ 8 \mathrm{hs}$ & $48,0 \mathrm{~b} \quad \mathrm{~A}$ & $45,5 b c A$ & $40,0 \mathrm{~b} \quad \mathrm{~A}$ & $44,5 \mathrm{c}$ \\
\hline$/ 16$ hs & $48,0 \mathrm{~b} \quad \mathrm{~A}$ & $48,0 \mathrm{abc} A$ & $41,5 \mathrm{ab} A$ & $45,8 \mathrm{c}$ \\
\hline $124 \mathrm{hs}$ & $51,5 \mathrm{~b} \quad \mathrm{~A}$ & $46,5 \mathrm{abc} A$ & $42,9 \mathrm{ab} \quad A$ & $46,9 b c$ \\
\hline$/ 48 \mathrm{hs}$ & $52,5 \mathrm{~b}$ A & $45,0 \mathrm{bc} \mathrm{A}$ & $46,0 \mathrm{ab} A$ & $47,8 \mathrm{bc}$ \\
\hline$/ 72 \mathrm{hs}$ & $59,5 \mathrm{ab} A$ & $59,1 \mathrm{a} \quad \mathrm{A}$ & $43,0 \mathrm{ab} \quad \mathrm{B}$ & $53,9 \mathrm{ab}$ \\
\hline $196 \mathrm{hs}$ & $66,0 \mathrm{a} A$ & $53,5 \mathrm{ab} \mathrm{B}$ & $54,0 \mathrm{a} \quad \mathrm{B}$ & $57,8 \mathrm{a}$ \\
\hline Média & 53,0 A & $48,6 \quad B$ & $43,3 \quad C$ & \\
\hline Lote B/ 0 hs & $70,0 \mathrm{ab} A$ & $70,0 \mathrm{a} \quad \mathrm{A}$ & $70,0 \mathrm{a} \quad \mathrm{A}$ & $70,0 \mathrm{a}$ \\
\hline $12 \mathrm{hs}$ & $67,6 \mathrm{ab} \mathrm{A}$ & $61,0 \mathrm{ab} A$ & $58,6 \mathrm{abc} \mathrm{A}$ & $62,4 a b$ \\
\hline$/ 4 \mathrm{hs}$ & $58,5 \mathrm{ab} \mathrm{A}$ & $61,1 \mathrm{ab} A$ & $53,0 \mathrm{bcd} A$ & $57,5 b$ \\
\hline $16 \mathrm{hs}$ & $60,5 \mathrm{ab} A$ & $46,6 b \quad B$ & $60,5 \mathrm{abc} A$ & $55,9 b$ \\
\hline $18 \mathrm{hs}$ & $55,5 \mathrm{~b} \quad \mathrm{~A}$ & $56,6 \mathrm{ab} A$ & $52,0 \mathrm{bcd}$ A & $54,7 b$ \\
\hline$/ 16 \mathrm{hs}$ & $70,5 \mathrm{a} \quad \mathrm{A}$ & $63,6 \mathrm{a} \quad \mathrm{A}$ & $47,0 \mathrm{bcd}$ B & $60,4 b$ \\
\hline$/ 24 \mathrm{hs}$ & $64,2 \mathrm{ab} \mathrm{A}$ & $63,5 \mathrm{a} \quad \mathrm{A}$ & $41,0 \mathrm{~d} \quad \mathrm{~B}$ & $56,2 b$ \\
\hline$/ 48 \mathrm{hs}$ & $65,0 \mathrm{ab} \mathrm{A}$ & $56,0 \mathrm{ab} \quad \mathrm{A}$ & $40,4 d \quad B$ & $53,8 \mathrm{~b}$ \\
\hline$/ 72 \mathrm{hs}$ & $64,1 \mathrm{ab} \mathrm{A}$ & $65,5 \mathrm{a} \quad \mathrm{A}$ & $44,0 \mathrm{~cd}$ B & $57,9 b$ \\
\hline$/ 96 \mathrm{hs}$ & $70,6 \mathrm{a} \quad \mathrm{A}$ & $62,5 \mathrm{a} \quad \mathrm{A}$ & $42,4 \mathrm{~d} \quad \mathrm{~B}$ & $58,5 \mathrm{~b}$ \\
\hline Média & $64,7 \quad A$ & $60,7 \quad B$ & $50,9 \quad \mathrm{C}$ & \\
\hline
\end{tabular}

Médias seguidas pela mesma letra minúscula na coluna e maiúscula na linha, para cada lote, não diferem significativamente entre si a $5 \%$. 
TABELA 5 - Teor de agua de sementes de mucuna-preta rectm-colhidas, procedentes de Adamantina (lote A) e de Votupsranga (lote B), ap6s diferentes perfodos de exposiģa a calor seco, a diversas temperaturas.

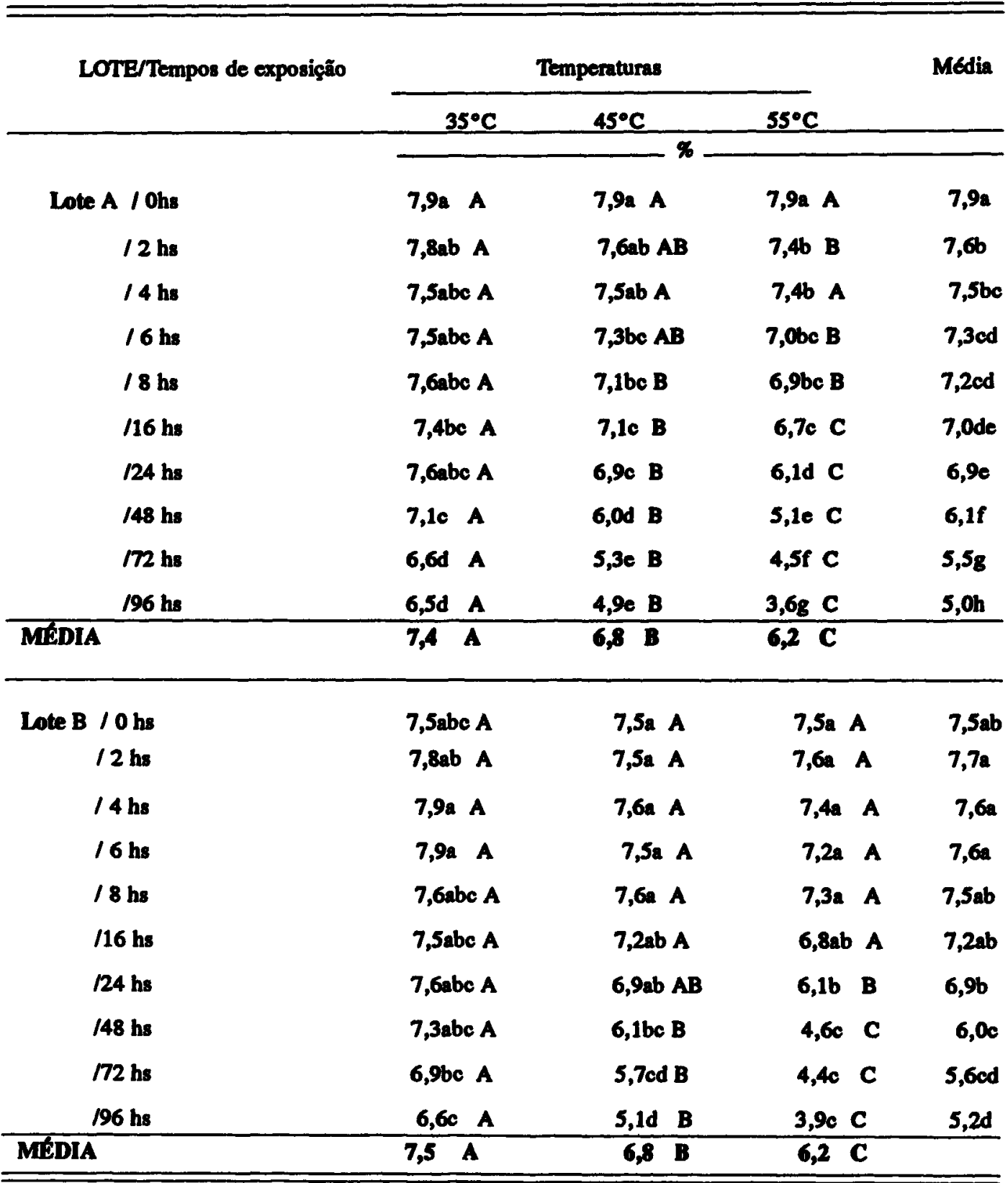

CV $\%=1,03 \%$ (lote A) e 2,28\% (lote B).

Médias seguidas pela mesma letra minúscula na coluna e maiúscula na linha não diferem significativamente entre si a $5 \%$. 


\section{CONCLUSÃo}

A exposição de sementes recém-colhidas e não escarificadas de mucuna-preta à temperatura de $55^{\circ} \mathrm{C}$ por perfodos de exposição entre 16 e 24 horas $\varepsilon$ uma possibilidade viável para melhoria do seu poder germinativo, podendo ser utilizada em larga escala.

\section{REFERENCIAS BIBLIOGRAFICAS}

ALMEIDA, L.D.A.; MAEDA , J.A.; FALIVENE, S.M.P. Efeitos de métodos de escarificação na germinação de sementes de cinco leguminosas forrageiras. Bragantia, Campinas, v.38, p.83-96, 1979.

ÁQUILA, M.S.A.; FETT NETO, A.G. Influência de processos de escarificação na germinação e crescimento inicial de Leucaena leucocephala (Lam.) DeWit. Revista Brasileira de Sementes, Brasilia, v.10, n.1, p.73-85, 1988.

ARAÚJO, E.F.; ARAUJO, C.F.; ARAÚJo, R.F.; GALVÃO, J.C.C.; SILVA, R.F. da. Efeito da escarificação das sementes e dos frutos de Stylosanthes guianensis (Aubl.) SW na germinaçäo. In: CONGRESSO BRASILEIRO DE SEMENTES,9., Florianópolis, 1995. Resumos. Informativo ABRATES, Brasilia, v.5, n.2, p.190, 1995.

BARBEDO, C.J.; NAKAGAWA, J.; MACHADO, J.R. Efeitos do tamanho e do armazenamento na dormência de sementes de mucuna-preta. Cientifica, São Paulo, v.16, n.1, p.97-104, 1988.

BEWLEY, J.D.; BLACK, M. Physiology and biochemistry of seeds. Berlin, Springer-Verlag, 1982. 2 v.

BRANT, R.E.; McKee, G.W.; CLEVELAND, R.W. Effect of chemical and physical treatment on hard seed of Penngift crownvetch. Crop Science, Madison, v.11, p.1-6, 1971.

BRASIL. Ministério da Agricultura. Regras para analise de sementes. Brasília: SNAD/DNDV/CLAV, 1992. 365 p.

BRUM, E.; MATTEI, V.L.; SCHUCH, L.O.B.; STAHLSCHMIDT, N.R. Superaçāo de dormência em sementes de acácia trinervis (Acacia longifolia Willd). In: CONGRESSO BRASILEIRO DE SEMENTES, 9., Florianópolis, 1995. Resumos... Informativo ABRATES, Brasilia, v.5, n.2, p.93, 1995.
CfCERO, S.M. Dormência de sementes. In: SEMANA DE ATUALIZAÇĀo EM PRODUÇĀO DE SEMENTES, 1., Campinas, 1986. Campinas: Fundagão Cargill, 1986. p.41-76.

DUBOC, E.; SANTANA, D.G.; CARVALHO, M.L.M.; VIEIRA, M.G.G.C. Efeito do tratamento de quebra de dormencia nos resultados do teste de envelhecimento acelerado em sementes de Leucaena leucocephala. In: CONGRESSO BRASILEIRO DE SEMENTES, 8., Foz de Iguaçu, 1993. Resumos... Informativo ABRATES, Brasilia, v.3, n.3, p.120, 1993.

EIRA, M.T.S.; FREITAS, R.W.A.; MELLO, C.M.C. Superaçăo da dormência de sementes de Enterolobium contortisiliquum (Vell.) Morong -Leguminosae. Revista Brasileira de Sementes, Brasilia, v.15, n.2, p.177-181, 1993.

ELLIS, T.J.; PALMER, T.P. Heat treatment of hard seed in lucerne. New Zealand Journal of Experimental Agriculture, Wellington, v.1, p.44-45, 1973.

FIGUEREDO, F.J.C.; POPINIGIS, F. Superação da dormência de sementes de maiva. Revista Brasileira de Sementes, Brasilia, v.1, n.3, p.1-13, 1979.

GOMES, F.P. A estatistica moderna na pesquisa agropecuária. Piracicaba: POTAF́́s, 1984. 160 p.

HARRINGTON, J.F. Hard seeds in bean and other legumes. Seed World, Chicago, v.64, p.42-44, 1949.

JESUS, R.M.; PIN̄A-RODRIGUES, F.C.M. Programa de produçāo e tecnologia de sementes florestais da Floreatas Rio Doce S.A.: uma discussāo dos resultados obtidos. In: SIMPÓSIO BRASILEIRO SOBRE TECNOLOGIA DE SEMENTES FLORESTAIS, 2 ., Atibaia, 1989. Annis... São Paulo: Instituto Florestal, 1991. p. 59-86.

LAGO, A.A. do; MARTINS, L. Qualidade fisiologica de sementes de Brachiaria brizantha 'Marandu'. In:CONGRESSO BRASILEIRO DE SEMENTES, 9 ., Florianópolis, Informativo ABRATES, Brasilia, v.5, n.2, p.123, 1995.

MAEDA, J.A.; LAGO, A.A. do. Germinação de sementes de mucuna-preta após tratamentos para superação da impermeabilidade do tegumento. Revista Brasileira de Sementes, Brasília, v.8, n.1, p.79-84, 1986a.

MAEDA, J.A.; LAGO, A.A. do. Longevidade de sementes de algumas espécies de mucuna. Bragantia, Campinas, v.45, n.1, p.189-194, 1986 b. 
MALUF, A.M. Variagto populacional m germinagto de Senna mulajuga. In: CONGRESSO NACIONAL SOBRE ESSENCLAS NATIVAS, 2., Sto Paulo, 1992. Annis... S5o Puulo, Intituto Floreatal, 1992. p.728732.

MEDEROS, R.B.; NABINGER, C.; SOUZA, H.E. Trutamentos pre- serminativos em sementes de leguminosasforrageiras. In:CONGRESSO BRASILEIRO DE SEMENTES, 8., Foz de Iquagú, 1993. Resumos... Informative ABRATES, Bresilia, v.3, n.3, p.70, 1993.

NIMER, R.; CARVALHO, N.M.; LOUREIRO, N.; PERECINO, O. Influência de aiguns fatores da planta sobre o grau de dormencia em sementes de mucuna-preta. Revista Brasileira de Sementes, Brasflia, v.5, n.2, p.111-119, 1983.
ROLSTON, M.P. Wher impermenble seed dormangy. Butmical Revion, Bxonx, v.44. n.3, p.365-396, 1978.

SHARI, A. Some factors affecting dormancy breaking in peamut seeds. Seed Science and Technolosy, Zurich, v.6, n.3, p.655-660, 1978.

TRAN, V.N.; CAVANAGH, K. Structural aspects of dormancy. In:MURRAY, D.R. (Ed.). Seed phyciology. New York: Academic Prese, 1984. v.2, p.1-44.

Recebido para publicação em 07.06 .95

Aceito para publicação em 04.07.95 